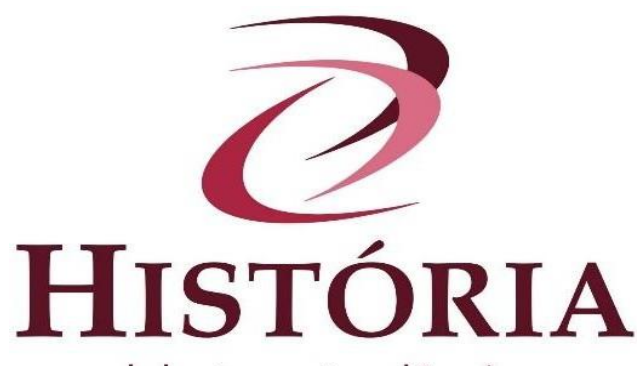

debates e tendências

\title{
O projeto da Frente Popular e a crise política no Brasil
}

\author{
The Popular Front project and the political crisis in Brasil
}

\section{O proyecto del Frente Popular y la crise política en Brasil}

Vitor Wagner Neto de Oliveira*

\begin{abstract}
Resumo: A proposta deste texto é pensar a crise política no Brasil, a partir do marco das jornadas de junho de 2013, recorrendo ao debate acerca dos princípios, das estratégias e das táticas da esquerda que definiram os rumos seguidos pelo Partido dos Trabalhadores em sua política de alianças. As determinantes da crise também são encontradas na conjuntura política e econômica global e nacional, bem como na história recente de governos de Frente Popular na América Latina.
\end{abstract}

Palavras-chave: Brasil. Crise política. Frente Popular.

Abstract: The proposal of this text is to think about the political crisis in Brasil, starting from the mark of the journeys in June of 2013, recurring to the debate on the principles, strategies and tactics of the left that defined the courses followed by the Partido dos Trabalhadores in it's politic of alliances. The determinants of the crisis are also found on the political and economical global and national conjuncture, as well as in the recent history of Popular Front governments in Latin America.

Keywords: Brasil. Political Crisis. Popular Front.

Resumen: El propósito de este texto es pensar en la crisis política en Brasil, a partir del hito de las manifestaciones de calles de junio de 2013, recurriendo al debate sobre los principios, estrategias y tácticas de la izquierda que definieron las direcciones seguidas por el Partido dos Trabalhadores en su política de alianzas. Los determinantes de la crisis también se encuentran en la coyuntura política y económica mundial y nacional, así como en la historia reciente de los gobiernos del Frente Popular en América Latina.

Palabras clave: Brasil. Crisis política. Frente Popular.

\section{Introdução}

Inicio este texto com um quase poema, uma quase poesia social de um pensador militante que nasceu há 200 anos: "Cada partido ataca por trás aquele que procura empurrá-lo para a frente e apoia-se pela frente naquele que o empurra para trás. Não é de admirar que nessa 
postura ridícula perca o equilíbrio e, feitas as inevitáveis caretas, caia por terra em estranhas cabriolas.” (MARX, 2008, p.48)

O trecho acima, dito por Marx no 18 Brumario na análise magistral do processo revolucionário francês, é introdutório e ao mesmo tempo pode ser uma síntese da história do Partido dos Trabalhadores (PT) no Brasil que chegou ao governo com a conformação de uma Frente Popular. Entro num debate espinhoso não só por se tratar de um tema de história do tempo presente - ainda com um devir, com um vir a ser -, mas especialmente porque mexe com paixões políticas de parte da esquerda brasileira e latino-americana. Parto de Marx porque o debate proposto é a partir da perspectiva de esquerda (e não da crítica à direita), ou seja, de uma análise que requer o retorno ao método crítico, como ensinado pelo próprio Marx.

O trecho acima, do 18 Brumario, foi escrito em 1852, no entanto a atualidade é desconcertante. E por que é assim tão atual? Porque, guardadas a distância temporal e a revolução tecnológica, ainda vivemos em um mundo muito semelhante ao do século XIX. Um mundo capitalista, dos estados-nacionais, em que a política governa as vidas no lastro dos interesses da classe dominante e da defesa do capital.

Como sabemos, o livro 18 Brumario compõe uma trilogia de escritos que buscava compreender a situação revolucionária na França na segunda metade do século XIX. Antes dele veio a público em 1850 o Lutas de classes na França em que o autor desenvolveu a sua teoria da revolução ou teses para táticas revolucionárias do proletariado (MARX, 2012). E o terceiro, publicado em 1871, foi intitulado A guerra civil na França em que relata e analisa a primeira experiência de governo proletário e a repressão das forças militares de Versalhes às comunas (MARX, 2011). Mas é mesmo em O 18 Brumario de Luís Bonaparte que Marx analisa de forma magistral o papel da luta de classes como força motriz da história e aprofunda a teoria do Estado. Nesta obra Marx propõe, pela primeira vez, a tese de que o proletariado não deve assumir o aparato existente, mas destruí-lo.

Por que abordar a crise política que se agravou no Brasil a partir de 2013, com o clássico de Marx? Será porque a história se repete? A resposta talvez esteja na mesma obra citada, quando Marx completa a ideia de Hegel de que: “os fatos e personagens na história ocorrem duas vezes", "a primeira vez como tragédia, a segunda como farsa” (MARX, 2008, p.39).

Mas, o que é tragédia e o que é farsa nessa história? O impeachment de Dilma em 2016 seria a farsa do que foi a tragédia de 1964 (golpe empresarial-militari)? Ou ainda por que 2016 é a farsa do que foi a tragédia de 1992 (impeachment de Fernando Collor)? Em que pese as aproximações possíveis, não vejo repetições, especialmente 2016 em paralelo a 1964. 
Não que um golpe civil-militar esteja para sempre fora de cogitação no Brasil, como na América Latina que tem em suas veias a tradição do Estado autoritário. Não. As forças armadas se arrogam o papel de manter a ordem burguesa. Portanto, quando esta ordem for seriamente ameaçada essas forças militares podem se colocar em ação em conjunto às forças mais conservadoras que a elas se aliarão. E aqui novamente o 18 Brumario:

Imaginai agora o burguês [...], o seu cérebro comercialmente enfermo, torturado na agonia desse pânico comercial, girando estonteado pelos boatos de golpes de Estado [...], pela luta entre o Parlamento e o Poder Executivo [...], pelas conspirações comunistas [...], pela propaganda de diversos candidatos à presidência, pelas palavras de ordem dos jornais que lembravam os pregões de vendedores ambulantes [...] pensai em tudo isso e compreendereis a razão pela qual em meio a essa incrível e estrepitosa confusão de revisão, fusão, prorrogação, Constituição, conspiração, coligação, usurpação e Revolução, o burguês berra furiosamente para a sua república parlamentar: Antes um fim com terror, do que um terror sem fim! (MARX, 2008, p.104)

Para o burguês, antes o terror da ditadura do que um terror sem fim da instabilidade política. Mas não é este o caso, ao menos na conjuntura brasileira aqui analisada.

Inicio o texto retomando Marx porque nesta obra, em especial, o autor descortina todas as tramas palacianas de uma crise política profunda. A profundidade da análise de Marx está não na narrativa dos acontecimentos, nas tramas superficiais, mas na enunciação dos nervos que ligam essas tramas, os fatos e os personagens à conformação das classes sociais, à estrutura da sociedade. Minha análise, contudo, não aborda as tramas palacianas e a história política a partir de personagens diversos, como fez Marx. Pelos limites de um artigo como este, a proposta aqui é mais simples: pensarmos a crise brasileira para além das aparências, para além da superficialidade dos debates parlamentares, das expressões esdrúxulas nas tribunas do parlamento, ou do brado da burocracia sindical e cúpulas partidárias. Ir um pouco mais a fundo pode nos levar a perceber que as expressões do conservadorismo e reacionarismo são partes de uma "cultura política", portanto determinadas pelas relações sócio históricas.

\section{Uma breve história: do PT das lutas para o PT das urnas}

A fundação do Partido dos Trabalhadores em fevereiro de 1980 foi fruto de um processo de grandes lutas contra a ditadura empresarial-militar, especialmente marcado por greves e mobilizações da nova classe operária em um país em urbanização acelerada. O Brasil ainda se encontrava sob a ditadura, mas os militares ensaiavam a abertura política, pressionados pelas grandes mobilizações, o que resultou em 1979 na Lei de Anistiaii que permitia o retorno dos perseguidos políticos e a Lei Orgânica dos Partidos Políticos ${ }^{\text {iii }}$ que autorizava a criação de partidos pondo fim ao bipartidarismo. A ideia de um partido que representasse os anseios da classe operária foi lançada no IX Congresso dos Metalúrgicos de São Paulo, ocorrido em 1979 na cidade de Lins, estado de São Paulo, e logo conseguiu aglutinar lideranças dos trabalhadores 
urbanos, rurais, da intelectualidade de esquerda, dos movimentos sociais de negros/negras, mulheres, movimento estudantil e agentes pastorais e leigos inspirados na Teologia da Libertação. O PT surgiu democrático em vista da soma de diversas correntes com concepções de esquerda moderada a radical que lutavam contra a ditadura. A militância do PT se enraizou nos movimentos social e sindical e no fluxo das grandes greves fundou, em 1983, o que viria a ser a maior organização dos trabalhadores da América Latina, a Central Única dos Trabalhadores (CUT), fundamental na reorganização da classe operária.

O PT também cresceu rápido eleitoralmente, ao passo que na primeira eleição para deputado em que o partido pode se inscrever, ainda na ditadura em 1982, elegeu 8 deputados federais, e na primeira eleição pós-ditadura, em 1986, o PT aumentou a representação parlamentar federal em mais de 100\% elegendo 17 deputados, incluindo Luiz Inácio Lula da Silva, o campeão de votos, para o mandato que construiu a nova Constituição sancionada em 1988. E seguiu numa crescente chegando a 91 deputados em 2002, quando elegeu Lula como presidente.

O desempenho eleitoral de Lula para a presidência também acompanhou o ritmo de crescimento do Partido no campo eleitoral. Lula disputou a presidência pela primeira vez em 1989 (primeira eleição direta para presidente após a ditadura), depois em 1994, 1998 e 2002 quando foi eleito no segundo turno com mais de 60\% dos votos válidos. A partir de 1994 as eleições passaram a polarizar os projetos do Partido da Social Democracia Brasileira (do sociólogo liberal Fernando Henrique Cardoso-FHC) e do PT que ampliou cada vez mais o escopo de alianças. A coligação “Frente Brasil Popular” que lançou Lula em 1989 era composta pelo Partido Socialista Brasileiro (PSB) e pelo Partido Comunista do Brasil (PCdoB), caracterizando uma Frente Única $^{\text {iv }}$ capitaneada pelo PT. Em 1994 repetiu-se a aliança com PSB e PCdoB, ampliando a frente no campo da esquerda com Partido Popular Socialista (PPS) ${ }^{\mathrm{v}}$, Partido Verde (PV) e o Partido Socialista dos Trabalhadores Unificados (PSTU) ${ }^{\text {vi }}$. O nome da coligação de 1994 também indicava uma mudança substancial: à consigna "Frente Brasil Popular" de 1989 acrescentou-se a "cidadania” (Frente Brasil Popular pela Cidadania), indicando o caminho que seria aprofundado a partir de então, se distanciando da caracterização de classe.

Em 1998 a coligação "União do Povo Muda Brasil” uniu PT, PSB, PCdoB, PCB e mais o Partido Democrático Trabalhista (PDT), do tradicional Leonel Brizola. Mesmo ampliando a frente Lula foi derrotado pela segunda vez pelo liberal FHC. Em 2002 Lula conseguiu derrotar José Serra, do PSDB, ampliando a aliança à direita com o Partido Liberal (PL), Partido da Mobilização Nacional (PMN), além de PCB e PCdoB (mais os que se somaram 
no segundo turno PPS, PDT, PTB, PSB, PGT, PTC, PV e PHS). A unidade desta diversidade foi sintetizada na denominação da coligação - "Lula Presidente" - que indicava de um lado a personificação do projeto do PT na figura de Lula da Silva (não mais o "Povo", o "Brasil popular" ou a "Mudança", apenas "Lula Presidente"), e de outro a configuração de uma Frente Popular em torno de um projeto liberal, simbolizado não só pelos partidos apoiadores, mas também no candidato a vice-presidente, o industrial e político de Minas Gerais, José Alencar, do Partido Liberal. ${ }^{\text {vii }}$

A história do PT e de Lula é uma curva suave e constante à direita, que teve uma inclinação maior quando da configuração da Frente Popular levando-a à vitória em 2002. Por isso a Frente é também o ponto culminante de dois movimentos complementares: do declínio à direita e da ruptura com o projeto de classe. A "Carta ao povo brasileiro", lida pelo candidato Lula em 22 de junho de 2002, foi a expressão pública do acordo que possibilitou a aliança de diversos partidos em torno de sua candidatura. A carta era ao "povo", mas também e principalmente aos agentes do capital financeiro e grandes empresários que estavam temerosos com a possibilidade de um ex-operário sindicalista chegar à presidência. Na carta Lula destacava o apoio crescente à candidatura que simbolizava "um projeto de mudança do Brasill":

Lideranças populares, intelectuais, artistas e religiosos dos mais variados matizes ideológicos [...]. Prefeitos e parlamentares de partidos não coligados com o PT anunciam seu apoio. Parcelas significativas do empresariado vêm somar-se ao nosso projeto. Trata-se de uma vasta coalizão, em muitos aspectos suprapartidária, que busca abrir novos horizontes para o país. viii

Demonstrar o apoio para além da sua base tradicional, dos trabalhadores, era necessário para evidenciar que não se tratava mais de um candidato e de um partido que governaria para os trabalhadores, mas sim para "todos" e daí a "vasta coalizão", num esforço de "salvação nacional" diante da crise econômica, derivada, conforme a carta, da política financeira adotada por FHC na década de 1990 quando passou a ancorar o Real ao Dólar.

A solução apontada pelo candidato representante da coalizão não era a ruptura com o modelo, em que pese prometer outro Brasil sob seu comando. A solução viria da ampliação da inserção do Brasil no mercado mundial, mas com "soberania". Para tanto, admitia fazer reformas reivindicadas pelos capitalistas, como a tributária, a previdenciária e a trabalhista. No mesmo bojo dessas pautas aparecem na carta as reformas reivindicadas pelos movimentos sociais que apoiavam Lula, como a reforma agrária: “O caminho da reforma tributária, que desonere a produção. Da reforma agrária que assegure a paz no campo. Da redução de nossas carências energéticas e de nosso déficit habitacional. Da reforma previdenciária, da reforma trabalhista e de programas prioritários contra a fome e a insegurança pública.” 
Ao colocar no mesmo escopo elementos contrapostos - como de um lado a desoneração da produção, as reformas trabalhista e previdenciária que para os capitalistas significava, entre outras, a redução dos custos com a força de trabalho, e de outro a reforma agrária, a habitação e o combate à fome - Lula parecia condicionar a concessão ao capital a atender parte da pauta da população pobre. Para tanto, e como forma de ressaltar que se tratava de um novo tempo, de uma ruptura, o candidato destacou a democracia com base em um novo pacto social:

O novo modelo não poderá ser produto de decisões unilaterais do governo, tal como ocorre hoje, nem será implementado por decreto, de modo voluntarista. Será fruto de uma ampla negociação nacional, que deve conduzir a uma autêntica aliança pelo país, a um novo contrato social, capaz de assegurar o crescimento com estabilidade. ${ }^{\text {ix }}$

As bases para o novo "contrato social" estavam lançadas: "o respeito aos contratos e obrigações do país". Essa era a mensagem ao "mercado". E o que viria logo nos primeiros meses de governo não contradisse o enunciado.

A coalizão venceu as eleições e levou o ex-operário sindicalista à presidência. Com ele chegou também a esperança de milhões de trabalhadores e trabalhadoras, de milhares de lideranças sindicais e de movimentos sociais com suas pautas, de intelectuais, artistas e pessoas comuns. A posse em Brasília no dia 1 de janeiro de 2003 foi um ato público, até então nunca visto, com milhares de pessoas com suas bandeiras vermelhas e faixas lembrando os temas que esperavam fosse atendidos pelo presidente. Foi uma grande festa:

Sob a égide da palavra de ordem 'A esperança venceu o medo' uma maré vermelha tomou as ruas e as praças. Nunca se vira coisa igual. Manifestações como essa, talvez, só no clima da conquista da Copa do Mundo. O desafio agora era outro: o de governar este país. Cada um parecia ser um governante. A posse foi apoteótica. Os trabalhadores romperam o protocolo e, simbolicamente, tomaram posse também. (DIAS, 2006, p.144)

\section{Do PT das urnas ao governo de Frente Popular}

Ao classificar a coligação que levou o PT ao governo em 2002 de Frente Popular (FP) estou me referindo a política que teve sua delineação na III Internacional Comunista para os Partidos Comunistas (seções da IC) a partir de 1934, portanto já no período stalinista. De ultraesquerdista, que combatia a tática da Frente Única com os sociais-democratas, Stalin passou a defender - e os stalinistas a impor aos PC - a política de Frente Popular com partidos de direita "democráticos" que se opunham à escalada do nazismo. Esta política na França surgiu em um contexto de avanço da luta operária, em 1934, que culminou com grandes greves em 1936, processo revolucionário derrotado em parte pela colaboração dos comunistas com a burguesia. Depois essa política se estendeu às demais seções da IC e foi a tática utilizada pelos stalinistas na Guerra Civil Espanhola (1936-1939). ${ }^{\mathrm{x}}$ Essa política, por conseguinte, fez parte da 
estratégia stalinista de "coexistência pacífica" com as democracias ocidentais no período da Guerra Fria e no escopo do "socialismo em um só país". Na América Latina tivemos vários exemplos, e no Brasil resultou na unidade do PCB com frações da burguesia em 1935 na Aliança Nacional Liberadora, quando Luis Carlos Prestes retornou da União Soviética e, na defesa do varguismo no final do Estado Novo, numa concepção "etapista" da revolução brasileira. ${ }^{\mathrm{xi}}$

A FP, como tática, não foi adotada somente pelas seções da III IC e nem se restringiu às décadas de 1930 e 40, pois esteve na conformação da candidatura de Salvador Allende, por exemplo, em 1970, no Chile. Portanto, a compreensão aqui é quanto ao conceito e a forma de se construir alianças políticas a partir de partidos de esquerda, daí a diferenciação entre Frente Única (descrito na primeira parte deste artigo) e Frente Popular, e nessa discussão pode-se ainda acrescentar a noção de Frente Ampla que é retomada por alguns grupos ou militantes do PT e $\mathrm{PCdoB}^{\mathrm{xii}}$ na atualidade na perspectiva de ampliar as alianças após serem apeados do governo.

O debate acerca dos princípios, das estratégias e das táticas na esquerda é importante aqui para a compreensão dos rumos tomados pelo PT. A política de alianças deixa de ser uma tática e ganha centralidade na existência do PT porque participar de eleições deixou de ser tática e virou estratégia permanente, e ganhar eleições passou a ser o fator de sobrevida do partido. Daí a necessidade de ampliar mais e mais as alianças. Desenha-se um objetivo a longo prazo, apresentado à militância como um projeto estratégico do PT de reformas sociais ou do socialismo democrático (era comum entre a militância antes de o partido assumir o governo federal a expressão "a defesa do projeto!"), e a eleição como meio para efetivação dessa estratégia se torna ela mesma uma estratégia permanente, torna-se o objetivo. Quando esta confusão se estabelece há um distanciamento dos princípios, como a defesa do socialismo e a bandeira da ética que foi tomada como princípio pelo PT ainda na década de 1980 tendo em vista este tema ter centralidade no Brasil em vista do alto índice de corrupção na história brasileira. Uma vez no governo, a estratégia passa a ser manter-se no governo, defender a governabilidade, daí novamente as táticas de alianças.

A formação do primeiro governo Lula, na divisão dos ministérios, refletiu essa estratégia política - já anunciada na "Carta" acima referida - de "governabilidade" e aliança ampla, necessária para o objetivo maior que era recolocar o Brasil nos trilhos do desenvolvimento capitalista, voltar a crescer, para gerar emprego e renda, ou seja, nada de novo no front:

O segredo da esfinge se revelou. O ministério contemplou posições políticas muito diversificadas. A agricultura e o desenvolvimento diretamente sob controle dos empresários. A Fazenda reafirmou e radicalizou o acordo com o FMI. O Banco Central [...] era entregue a 
[Henrique Meirelles] um ex-dirigente máximo do Bank of Boston, segundo maior banco credor do Brasil e deputado eleito pelo PSDB. [...]. O 'mercado' ficou bem contemplado. Em grande medida, o segundo time, desse e de outros ministérios mantêm boa parte da equipe de Cardoso. (DIAS, 2006, p.144)

Henrique Meirelles permaneceu como presidente do Banco Central nos dois governos Lula, até 2011, sendo que em 2005 seu cargo passou a ter o status de Ministro de Estado, o que denota a centralidade que essa função ocupou no governo e ao mesmo tempo a autonomia de ação do Banco Central sob seu comando. Meirelles permaneceu como homem de referência na política econômica nos dois mandatos de Lula e no governo Dilma ocupou o cargo de Conselheiro Público Olímpico, responsável por coordenar o orçamento das obras do evento esportivo ocorrido em 2016. Até abril de 2018 foi ministro da Fazenda no governo de Michel Temer. A onipresença de Meirelles na política econômica brasileira se faz por ser um personagem que inspira confiança dos empresários e especuladores, daí ser peça chave, o liame entre o PT, a burguesia brasileira e o capital internacional. Por conseguinte, a volta de Meirelles como Ministro da Fazenda de Temer indicou que, de fundo, houve uma continuidade da política econômica nos governos Lula-Dilma-Temer.

O esforço de Lula para ter o respeito e a confiança da burguesia internacional surtiu efeito rápido. No primeiro mês de governo, dia 25 de janeiro de 2003, Lula teve oportunidade de falar aos capitalistas internacionais, quando discursou no Fórum Econômico Mundial de Davos arrancando aplausos efusivos dos presentes, especialmente do bilionário Georges Soros.

Na busca da conciliação entre capital e trabalho Lula propôs um "pacto social” com o objetivo maior do "desenvolvimento econômico". Neste sentido implementou também no primeiro ano de governo, em maio de 2003, o Conselho de Desenvolvimento Econômico e Social composto por empresários, sindicalistas, movimentos sociais e organizações não governamentais (ONG). Conforme Edmundo Dias (2006, p.148), nessa formulação Lula recriou "uma noção de classes produtivas", referência à composição do Conselho consultivo:

\footnotetext{
...é decisiva para a caracterização da natureza do Governo. Nele, os empresários têm um peso decisivo sendo mesmo mais da metade: cinco representantes do setor agropecuário, sete do setor financeiro (inclusive representantes de bancos internacionais [...]), o governo terá 10 ministros, 13 sindicalistas, dois da cultura, três de entidades de classe, 11 representantes de movimentos sociais (aqui entra Viviane Senna, o que mostra que as ONGs, além de serem confundidas com a Sociedade Civil, também o são com os Movimentos Sociais) e 2 religiosos. Participam ainda, além do Presidente, 2 representantes do Congresso Nacional: os deputados Delfim Netto (PPBSP) e Armando Monteiro Filho (PMDB-SP). (DIAS, 2006, p.152)
}

Um governo não se sustenta somente no discurso sem base na realidade. A proposta de fazer o país crescer economicamente tinha que se fazer e rápido, pois isso era o que afinal daria a liga que soldava a aliança ampla com o empresariado. Neste sentido, o ciclo de crescimento econômico aberto especialmente a partir do segundo ano de governo foi um fator determinante. 
O Produto Interno Bruto (PIB) cresceu constantemente de 2003 a 2014, e em 2015 o Brasil foi atingido pela crise mundial, agravada pela crise política, o que retraiu o PIB de forma drástica. Nos oito anos de governo FHC a média de crescimento do PIB foi de 2,5\%, nos oito anos de Lula foi de 4,1\% e no conjunto os governos de FP (Lula e Dilma) tiveram um desempenho na média de 2,9\%, considerando a redução de 3,9\% quando da recessão de 2015. O desempenho do PIB nos 13 anos de FP, portanto, foi próximo da era FHC. Neste sentido, Lula foi presidente no período áureo deste último e curto ciclo de crescimento.

Como país exportador de petróleo o valor desse produto foi um fator determinante para o bom desempenho do PIB nos dois mandatos de Lula. Em junho de 2014 o preço do barril atingiu o valor máximo de US\$114, em janeiro de 2015 o preço caiu abaixo de US\$50. ${ }^{\text {xiii }}$ A queda brusca no preço do produto também atingiu as finanças da maior estatal brasileira, a Petrobras, desvalorizando os papéis da empresa, o que contribuiu para a recessão. Outro fator que alguns analistas de mercado apontam é o impacto das investigações de corrupção, a "Lava Jato", que atingiu algumas das maiores empresas privadas do Brasil, as construtoras Odebrecht, OAS, Camargo Corrêa, Andrade Gutierrez, Queiroz Galvão, entre outras. ${ }^{\text {xiv }}$ Maria Lúcia Fatorelli $^{\mathrm{xv}}$, da organização Auditoria Cidadã da Dívida, aponta como principais causadores da crise as escolhas das políticas econômicas e monetárias dos governos brasileiros, como a adoção de juros elevados, as "operações compromissadas" que reduzem a quantidade de moeda em circulação e os gastos financeiros com a dívida pública.

A dívida pública é outro indicativo do desenvolvimento econômico do país, considerando os marcos da política da FP que objetivava melhorar tais índices. Em 2005 Lula anunciou que o Brasil deixara de ser devedor e passara a ser credor do FMI, pois havia pago a dívida externa. Anunciar o fim da dívida com o FMI, de um país que historicamente foi devedor, era importante para dar sinal da "saúde" financeira do Brasil. O que ocorreu, todavia, foi que o Brasil pagou apenas parte da dívida externa, ou seja, a que devia ao FMI e, para pagar o Fundo, cujos juros eram em torno de $4 \%$ ao ano, o Governo emitiu títulos da dívida interna que pagavam em torno de 19\%. Mesmo assim, o Ministério da Fazenda assumiu o compromisso de continuar obedecendo as determinações do FMI em relação à nossa política econômica que vigoram até hoje. ${ }^{\text {vi }}$ Por isso devemos considerar o montante da dívida externa e interna: em 2003, primeiro governo Lula, a dívida (externa e interna) alcançava $74 \%$ do PIB, desceu ao mínimo de 60\% em 2013 e voltou a crescer rápido na recessão de 2015 voltando aos 74\% do PIB. ${ }^{\text {xvii }}$ Em todo caso, os governos de FP mantiveram o sistema da dívida, cuja característica principal é o endividamento público via transferência de recursos do Estado ao setor financeiro. Para dar continuidade a esse sistema, até 2013 o governo realizou superávit primário a partir da 
redução de gastos públicos, enquanto a dívida crescia e consumia aproximadamente $\mathrm{R} \$ 1$ trilhão por ano e mais de $40 \%$ do Orçamento Geral da União.

Com o desempenho positivo da economia, o desemprego que era de $13 \%$ da população economicamente ativa em 2003, passou a recuar no segundo ano de governo Lula, seguindo a trajetória até alcançar o mínimo de 4,3\% em 2014, último ano do primeiro mandado de Dilma, conforme a metodologia da Pesquisa Mensal de Emprego (PME). Em outubro de 2015 a taxa de desemprego estava em 7,8\%, comparada à de 2008, e continuou a crescer em $2016(11,5 \%)$ e $2017(12,7 \%){ }^{\text {xviii }}$

O salário mínimo também é um indicador importante para analisarmos a economia do Brasil, pois é o índice que determina os salários dos aposentados pela Previdência Social, além de ser o valor mínimo mensal para um trabalhador formal. Somente aumentar o valor do salário mínimo não significa elevar o poder de compra do assalariado, por isso o crescimento real do salário deve considerar o que está acima da inflação. Neste sentido, no governo FHC o salário mínimo teve uma valorização real de 5,3\% na média anual, no mandato de Lula 9\% e de Dilma $3,2 \%$ até janeiro de 2016 . $^{\text {xix }}$

O desempenho positivo da economia, especialmente nos dois primeiros mandatos da FP, permitiu a implementação de algumas medidas que atendiam parte das reivindicações dos trabalhadores e da população pobre. O combate à miséria e à fome passou a ser uma bandeira importante, pois em um país com profundo abismo social, com milhões de pessoas abaixo da linha da pobreza, ${ }^{\mathrm{xx}}$ atacar esse problema era fundamental para a legitimidade do projeto da FP. Para tanto, a equipe do governo Lula reformou e ampliou 12 programas de transferência de renda criados por FHC a partir de 1999, entre eles Bolsa Alimentação, Bolsa-Escola e Programa de Erradicação do Trabalho Infantil. ${ }^{\text {xi }}$ No primeiro ano de governo de FP, em 2003, Lula criou o Ministério Extraordinário de Segurança Alimentar e Combate à Fome, transformado em 2004 no Ministério de Desenvolvimento Social e Combate à Fome, o que coloca o problema da pobreza extrema na centralidade das ações de governo. Os investimentos nos programas de renda mínima resultaram em uma sensível redução na desigualdade de renda familiar per capita, atingindo durante os dois primeiros mandados da Frente Popular o menor nível em 30 anos (MARINHO, LINHARES, CAMPELO, 2011, p.274), quando houve aumento médio anual de 5,01\% na renda familiar per capita entre 2003 e 2013, tendo reduzido a pobreza extrema em 6,05\% na média aproximadamente, no mesmo período (GODOY, RODRIGUES, 2017, p.205).

$\mathrm{O}$ aumento do PIB, per capita ou absoluto, não significa necessariamente maior riqueza distribuída, e isso é mais válido para países como o Brasil, de alta concentração de 
renda. Da mesma forma o aumento da reserva de dólares, que indica menor vulnerabilidade do país nos contextos de crises, não quer dizer menor vulnerabilidade do trabalhador. Mesmo os programas de "transferência" de renda, em que pese a diminuição da pobreza absoluta, não impactaram nos índices de concentração de renda, já que a acumulação de riqueza entre os mais ricos continuou inalterada. Conforme Souza, "entre o fim da década de 1980 e 2006, a combinação da entrada das mulheres na força de trabalho com os avanços educacionais e políticas sociais provocou uma redução razoável no Gini ${ }^{\text {xxii }}$. Desde então, a leve tendência de aumento da fração dos mais ricos acabou por anular os ganhos posteriores..." (SOUZA, 2016, p.269). Conforme o mesmo autor os programas sociais atingiram a parte de baixo da pirâmide de renda, ou seja, os mais pobres, todavia

Em virtude do grau de concentração entre os ricos, os limites dessa estratégia são bem estreitos, e não é por acaso que até nos dados originais das PNADs ${ }^{x x i i i}$ o ritmo da queda da desigualdade diminuiu bastante nos últimos anos. Entre 2005 e 2009, o Gini dos rendimentos individuais da população adulta caiu 4,9\%, contra uma redução de apenas 3,4\% entre 2009 e 2013 e estabilidade entre 2012 e 2013. Algo parecido ocorreu com o Gini da renda domiciliar per capita. (SOUZA, 2016, p.269)

A concentração se expressa de forma absoluta na apropriação de mais de $25 \%$ da riqueza por apenas $1 \%$ da população brasileira. Outra expressão da concentração de renda são os lucros do sistema financeiro, especialmente dos bancos: entre 1995 e 2002 (governo FHC) as nove maiores instituições brasileiras, incluindo os bancos estatais, tiveram lucro líquido de R\$ 30,798 bilhões a valores atuais (2011), enquanto que no governo Lula (2003 a 2010) lucraram R \$199,455 bilhões, ${ }^{\text {xxiv }}$ e o lucro continuou a crescer no governo Dilma. Medidas como a desoneração ou incentivo as montadoras de veículos e grandes empresas, para manter a produção no momento da recessão, a reforma da Previdência Social do funcionalismo público federal, que criou fundos de pensão privada, foram ações que também favoreceram essa concentração.

No que se refere à política econômica, portanto, percebe-se uma continuidade entre o governo liberal de FHC e o de Frente Popular Lula/Dilma. O projeto de governo da FP se sustentou no breve crescimento econômico que permitiu implementar algumas medidas compensatórias como programas de governo e não políticas de Estado, as quais foram reduzidas ou eliminadas a partir da intensificação da crise em 2014 e especialmente com o advento do governo Michel Temer e o seguinte.

\section{Os sindicatos e movimentos sociais: das ruas ao Planalto... E as ruas novamente}

Desde 1986 o PT passou a ocupar espaço no legislativo e executivo das três esferas da federação (municípios, estados e união), e desde que passou a ocupar o executivo em prefeituras 
e estados se tornou recorrente no campo de esquerda no Brasil o debate acerca da relação entre governo e movimentos sociais. Por vezes esse debate fora expresso na contradição de ser um partido governo que se sustentava na relação orgânica com os movimentos sociais e sindicatos de esquerda. Quando a FP chegou ao governo em 2003 esse debate se fez maior, e a contradição se expressou de forma mais explícita. A maior central sindical do país (a CUT), o maior movimento camponês (o Movimento dos Trabalhadores Sem-Terra - MST) e a maior organização estudantil (a União Nacional dos Estudantes - UNE), e dezenas de movimentos urbanos de pautas variadas, passaram a apoiar o governo, por vezes de forma incondicional. Foram poucos os sindicatos e movimentos sociais que se colocaram na oposição de esquerda, que não aderiram à órbita do PT. A adesão significou a defesa do governo diante dos ataques vindos especialmente da esquerda, por isso as rupturas neste campo. Uma das expressões dos debates e contradições no movimento sindical, pós-2003, é a fragmentação sindical com a criação de dezenas de sindicatos e centrais sindicais (15 organizações), nem sempre no espectro da esquerda, mas que não significou necessariamente o aumento no número de sindicalizados que permaneceu próximo do mesmo no período pós-2003.

Conforme Alexandre Pimenta (2018, s/p) “A ampliação de números de sindicatos/centrais foi acompanhada por um esvaziamento dos mesmos. As instituições que cresceram, e não a quantidade de trabalhadores nelas, uma espécie de crise de representatividade". Em 2006 houve um pico no número de sindicalizados, chegando a 21\% dos trabalhadores ocupados maiores de 18 anos, a partir de então decresceu até 16,6\% em 2013 (CARDOSO, 2015, p.596). Ainda segundo Pimenta (2018, s/p) “O distanciamento do movimento sindical das bases é concomitante à aproximação com o Estado/Governo [...]. Os sindicatos no Brasil se tornaram, no ciclo petista, cada vez mais um setor cristalizado na máquina estatal, sobretudo através da maior central sindical, a CUT [...].”

Por outro lado, a adesão não significou ausência de enfrentamentos, especialmente quando se tinha uma base sindicalizada, por exemplo, que impunha a greve à direção dos sindicatos, ou mesmo da iniciativa de sindicatos de oposição. Neste sentido, o número de greves é um termômetro dessa dinâmica de adesão da cúpula e enfrentamento. Após um pico no ano de 1996 com 1.228 greves (sendo 374 na esfera pública - órgãos do Estado e em empresas estatais -, 850 na esfera privada e 4 conjuntas entre as duas esferas pública e privada), tem-se um descenso persistindo o declínio até 2005 quando retoma o ascenso chegando ao pico em 2013. Comparativamente tem-se 877 greves em 2012 (410 na espera pública, 464 na esfera privada e 3 nas duas esferas) e 2.050 em 2013 (933 na esfera pública, 1.106 na esfera privada e 11 unindo as duas esferas). ${ }^{\mathrm{xxv}} \mathrm{O}$ salto de greves de $127.6 \%$ entre os trabalhadores públicos e de 
372,4\% entre os trabalhadores de empresas privadas de 2012 para 2013 é um dos indicativos de uma crise política que se abriu nas “jornadas de junho", assim denominado o movimento de rua que sacudiu o país em 2013. Aquelas manifestações quebraram a estabilidade político-social e desde então a situação política foi marcada por instabilidade.

Milhões de pessoas foram às ruas de centenas de cidades. A fagulha que acendeu a revolta popular foi o aumento de $\mathrm{R} \$ 0,20$ (vinte centavos de real) no valor do transporte coletivo na capital de São Paulo. A resistência do prefeito municipal, do PT, em cancelar o aumento e a repressão da polícia do governo do Estado comandado pelo PSDB, fez crescer a mobilização convocada pelo Movimento Passe Livre, formado especialmente por jovens. Logo foi numa crescente e extrapolou a pauta do transporte, da juventude e da cidade, com a adesão da juventude e dos trabalhadores de centenas de cidades, com a depredação de prédios símbolos do poder e, no caso de Brasília, com a tomada da abobada da Câmara dos Deputados e até do Palácio do Planalto, residência da presidente Dilma. Apesar de bastante difusa, a pauta de milhões de pessoas que tomaram as ruas foi marcada pelo descontentamento com o governo e os políticos de uma forma geral, e o questionamento aos gastos com obras para a Copa da FIFA que o Brasil sediaria em 2014. “A política se faz nas ruas!”, essa era a mensagem de Junho. Um descontentamento difuso, mas que tinha como fundo a repulsa à forma de se fazer política de bastidores, que incluiu, em um segundo momento, a recusa aos partidos de direita e de esquerda, e aos sindicatos. ${ }^{\text {xxvi }}$

A elevação abrupta no número de greves em 2013, comparado ao período anterior, se insere, portanto, neste contexto que desata a crise política que terá desdobramentos não previstos. A tentativa de Dilma de trazer os movimentos sociais para o diálogo com a formação de um conselho de representantes de movimentos sociais e sindical em 2014 não surtiu efeito até pela reação contrária do empresariado e dos deputados que interpretaram como uma tentativa de substituir a casa legislativa na mediação com o executivo. No ano da Copa da FIFA e de eleição presidencial, na tentativa de manter o controle diante das manifestações contrárias à realização do evento esportivo que envolvia enormes gastos, o governo recorreu à força militar e de polícia, o que denota a intensificação da crise política agravada pelo envolvimento de figuras centrais dos partidos de sustentação do governo com a corrupção (PP, PMDB e PT). A reeleição de Dilma Rousseff (PT), em disputa acirrada com o senador Aécio Neves do PSDB, se deu neste marco conturbado de profundo questionamento do Partido da "ética na política" e dos movimentos sociais. A polarização, contudo, não interferiu no curso de elevação dos índices de não votantes, com alto índice de abstenção, votos nulos e brancos o maior desde 1998: 27\% dos eleitores, o equivalente a 38,6 milhões de pessoas, não votaram ou votaram em branco e 
nulo. ${ }^{\text {xxvii }} \mathrm{O}$ segundo turno das eleições de 2016 para prefeitos e governadores atingiu o recorde de abstenções, nulos e brancos (32,5\%). ${ }^{\text {xxviii }}$ Estes números chamam atenção ainda mais em se tratando de um país em que o voto é obrigatório. Refletiram, também, a falta de confiança dos brasileiros nas eleições que parecem determinadas pelo marketing e pelo poder econômico, como revelado nas investigações da operação "Lava Jato" nas doações milionárias das grandes empresas aos partidos e candidatos, tendo o PT como grande beneficiário. ${ }^{\text {xxix }}$

A crise econômica de 2014 tornou-se recessão em 2015 e acelerou a ruptura dos trabalhadores e da juventude com a FP, sobretudo quando Dilma Rousseff, na tentativa de se manter na presidência e manter a "governabilidade" impôs um ajuste fiscal que implicou cortes de investimentos na educação (de 11 bilhões anunciado no contexto da greve mais longa até então realizada pelos professores das universidades públicas federais), leis que limitaram o acesso do trabalhador ao seguro-desemprego (Lei 13.134/2015) e pensão por morte (Lei 13.135/2015). O governo então perdeu sua base de apoio e entrou numa espiral de crise, aprofundada pelas denúncias de corrupção.

A FP, contudo, não foi derrubada pelos trabalhadores organizados. Quem deflagrou a derrubada de Dilma foi a burguesia por meio da manobra do impeachment. A ruptura do governo com a classe trabalhadora deixou-o desamparado diante do ataque da burguesia. O PT confiou nas frações da classe dominante para se sustentar. Até 2015 algumas frações burguesas ainda hesitavam quanto à derrubada do governo de FP. Especialmente o setor financeiro, os bancos, essa fração ainda não estava totalmente convicta de que a melhor saída era a saída de Dilma.

O aprofundamento da crise política e econômica, todavia, levou a burguesia a concluir que a FP perdeu a condição de aplicar o programa de ajuste fiscal. Rompeu com o PT porque este não conseguiu recuperar a estabilidade nem aplicar o ajuste fiscal. Mesmo assim, alguns setores, ou indivíduos, como a ruralista Kátia Abreu, continuaram até o fim leais à Dilma. $\mathrm{O}$ impeachment teve sua versão também nas ruas, com manifestações de massa, em muitos casos capturadas pela burguesia, como os movimentos coordenados pela Federação das Indústrias do Estado de São Paulo (FIESP), aos quais a classe média aderiu volumosamente.

Os atos de rua que precederam o impeachment (desdobramento contraditório das Jornadas de Junho de 2013 e que se utilizou do novo método de mobilização - as redes sociais na internet), convocados pela palavra de ordem vaga "vem pra rua", foram atos essencialmente conservadores, como em outros momentos históricos, com programa igualmente conservador e neoliberal do ponto de vista econômico, acentuadamente racista, ideologicamente contrário à classe trabalhadora, contra pobres, contra os sindicatos, e antiesquerda (contra as bandeiras 
vermelhas, contra o comunismo identificado com o PT). Alguns setores minoritários tinham mesmo o apreço pelo fascismo ao defenderem a volta da ditadura e da tortura. Neste mesmo marco conservador as manifestações elogiavam instituições conservadoras como a Polícia Federal (e ressaltava-se a figura do juiz Sergio Moro que dirigia os trabalhos da operação "Lava Jato", como o "moralizador", o salvador da pátria), o Ministério Público e até a Polícia Militar. Uma posição conservadora, mas muito difusa (porque embasada num discurso contra a corrupção, incorporado por muitos trabalhadores, pessoas comuns e pobres).

Esta perspectiva foi canalizada em parte pelo candidato de ultradireita Jair Bolsonaro que despontou na corrida presidencial de 2018 como representante de uma "mudança" conservadora confluindo para si diversos movimentos, grupos e indivíduos heterogêneos, mas que encontram aí pontos de convergência. O pleito que elegeu Bolsonaro, contudo, não rompeu com o curso dos números que apontam para o descontentamento dos brasileiros com o sistema de representação eleitoral. Nas eleições de 2018, talvez a mais polarizada da "Nova República", o número de abstenções, 20,3\%, bateu o recorde de 1998 e somados com brancos e nulos chegou a $29,12 \%$ no primeiro turno, ${ }^{\mathrm{xxx}}$ e no segundo para presidente atingiu $30,84 \%$ sendo que o voto nulo bateu o recorde de 1989 , com 7,4\%. Foram 42,1 milhões de pessoas que não escolheram nenhum dos candidatos do segundo turno. ${ }^{\mathrm{xxi}}$

Nessa conturbada conjuntura, os movimentos sociais, os sindicatos, os partidos e os intelectuais tentam estabelecer compreensões do movimento da história. Uma das explicações é sintetizada na caracterização da "onda conservadora" que parte da esquerda brasileira interpreta como sendo a expressão do período aqui analisado. Esta interpretação considera, portanto, o fim do governo de FP como um retrocesso por ter sido uma derrota não só do projeto da FP, mas do Estado de Direito, pois o impeachment teria sido forjado para colocar fim a um governo de esquerda.

A oposição de esquerda à FP apresenta outro entendimento para o período recente, o de que o Brasil vive uma "polarização" na luta de classes, e recusa, portanto, a caracterização de "onda conservadora". A base para este entendimento é a persistência das lutas sociais da juventude, como as ocupações de escolas e universidades em diversos estados em 2016 contra medidas dos governos federal e estaduais, e dos trabalhadores com o recorde na quantidade de greves no mesmo ano (2.093 no total, sendo 1.100 na esfera pública, 986 na esfera privada e 7 conjuntas) $)^{\text {xxii }}$, e nas greves e mobilizações de rua contra as reformas trabalhista e da previdência em 2017, levando à dois momentos de paralização generalizada dos trabalhadores em todo o país. 
Na perspectiva da primeira interpretação, da "onda conservadora", parece que de repente a sociedade brasileira se tornou conservadora! O otimismo por chegar ao governo parece que levou tal interpretação à perda de percepção de que nos 13 anos de governo de FP, em que pese avanços em alguns índices, continuaram ocorrendo dezenas de mortes, de desaparecidos e de prisões ${ }^{\text {xxxiii }}$ nos meios rural e urbano, motivados pela opressão de gênero e pela exploração de classe e raça. ${ }^{\text {xxiv }}$ A reforma agrária foi diminuindo até chegar ao limite de ser congelada; ${ }^{x x x v}$ as ocupações de terras, no mesmo caminho, diminuíram; a concentração de terras e a formação de latifúndios nunca foi tão intensa; as barreiras à legalização das retomadas de terras indígenas não foram derrubadas; ${ }^{x x x v i}$ ao passo que os diversos subsídios aos empresários (como benefícios fiscais, empréstimos subsidiados) entre 2003 e 2016 consumiu cerca de $\mathrm{R} \$ 1$ trilhão (um trilhão de reais) enquanto que para os programas sociais destinou-se R\$372 bilhões. ${ }^{\text {xxxvii }}$ Mesmo quanto a expansão do ensino superior, bastante utilizada pelo discurso petista como sendo o setor de grandes realizações, os números explicitam as contradições do projeto de FP: de 2003 a 2016 houve a ampliação de 62\% no número de matrículas, passando de 4.944.877 estudantes para 8.052.254, todavia, a maior parte se deu nas instituições privadas com 6.058.623 (75,3\%), enquanto que nas instituições públicas atingiu 1.990 .078 (24,7\%); no mesmo período o investimento na educação superior pública cresceu $144 \%$ e a destinação de recursos públicos para as instituições privadas via Fundo de Financiamento Estudantil cresceu 1069,27\%. ${ }^{\text {xxxviii }}$

Com todas essas contradições de um governo de FP, houve conquistas de bandeiras históricas dos movimentos como cotas para negros/negras e indígenas nas universidades, mais visibilidade da opressão machista, mais repercussão e mesmo conquista de direitos dos LGBT (como o reconhecimento civil das relações homoafetivas), implementação de projetos que vieram fortalecer a agricultura familiar a exemplo do Programa de Aquisição de Alimentos (PAA), entre outras ações. Conquistas arrancadas de uma sociedade conservadora.

A queda de Dilma Rousseff, representante do governo de Frente Popular, foi uma vitória da oposição burguesa. Essa é outra constatação. Não é uma vitória à esquerda, mas uma derrota à direita. Aqui novamente cabe uma citação do 18 Brumario, quando Marx caracteriza a burguesia republicana diante do golpe de Bonaparte: “Após terem (re)fundado uma república para a burguesia, expulsado do campo de luta o proletariado revolucionário e reduzido momentaneamente ao silêncio a pequena burguesia democrática, são eles mesmos postos de lado pela massa da burguesia, que com justa razão reclama essa república como sua propriedade". (MARX, 2008, p.39) 
O governo de transição, instalado no dia 12 de maio de 2016, tendo à frente o vicepresidente da FP, Michel Temer, passou a contar com o apoio de ampla maioria dos partidos no Congresso, os mesmos que votaram pelo impeachment de Dilma, para dar continuidade à aplicação das medidas de ajuste fiscal e reformas trabalhistas e sociais, reivindicados pelas burguesias financeira, industrial e agrária. Algo que o governo de FP estava com dificuldades de materializar em vista de ser mais sensível às pressões dos trabalhadores pela sua base popular, por isso foi trocado.

A posse de Temer deu início a um governo de unidade burguesa para desempenhar um papel semelhante ao que Itamar Franco desempenhou em 1992: lá o governo de transição de Itamar Franco possibilitou a eleição de FHC; aqui o de Temer pretendeu asfaltar o caminho para a eleição de alguém do PSDB, todavia, a crise econômica e política que permanecia em 2018 e o curso conjuntural de médio prazo aqui abordado, levaram à vitória da direita mais radical, de Jair Bolsonaro.

E o PT? De situação e aliado do PMDB este partido passou a oposição. Para sustentar essa localização no cenário político, construiu uma interpretação sua para o impedimento de Dilma, classificando como golpe parlamentar um processo que faz parte do jogo da democracia burguesa, jogo que o PT jogou enquanto ganhou ou ao menos achava que estava vencendo. Essa interpretação era necessária para manter o Partido como opção eleitoral na disputa para 2018. Lançou Lula da Silva como pré-candidato em defesa da estabilidade e do pacto social, tentando reconstruir o governo de FP. Mas a crise interburguesa que possibilitou a instituição da maior investigação sobre corrupção no Brasil, a Lava Jato, chegou até o então blindado exlíder operário e o presidente mais popular do país desde 1964, impedindo-o de se candidatar.

E então a história nos ensina que "como na vida privada se diferencia o que um homem pensa e diz de si mesmo do que ele realmente é e faz, nas lutas históricas deve-se distinguir mais ainda as frases e as fantasias dos partidos de sua formação real e de seus interesses reais, o conceito que fazem de si do que são na realidade". (MARX, 2008, p.44). O PT e Lula são personagens que se completam, e vida privada de Lula é a vida pública do PT. Daí a necessidade de construir uma narrativa que heroifique Lula e defenda o PT. Vivemos o ápice desse movimento de construção da narrativa heroificadora quando o juiz Sérgio Moro deu a ordem de prisão de Lula (e o Supremo Tribunal Federal aprovou em 16 de maio de 2018), o expresidente se alojou na sede do histórico Sindicato dos Metalúrgicos de São Bernardo dos Campos, onde começou sua militância como sindicalista na década de 1970. Para lá foram seus apoiadores, a CUT e representantes de movimentos sociais, de organizações sindicais e 
partidos, se mobilizaram no entorno do Sindicato, o que garantiu a protelação da prisão como um quase último ato de cristalização do herói.

No discurso de despedida, realizado após a celebração de uma missa em um palco montado na frente do Sindicato e televisionado na íntegra, Lula não economizou elogios aos diversos apoiadores que estavam no palanque. Nomeou cada um e destacou a presença dos précandidatos à presidência elo PCdoB e PSOL. Ao se dirigir à militância que estava no chão Lula procurou estabelecer uma conexão direta, carregada de simbolismos e subjetividade, e falou como se falasse para a população pobre de todo o Brasil.

Lula iniciou o discurso comparando o momento presente, de sua prisão, com a famosa greve metalúrgica de 1979 em que 100 mil trabalhadores reunidos no Estádio da Vila Euclides votaram pela continuidade da greve e contra o acordo que Lula e os demais diretores propuseram. Lembrou também da greve no ano seguinte, 1980, em que os metalúrgicos foram derrotados e asseverou os ganhos políticos, de "teoria política e tese política", em momentos de greve, mais do que ganhos financeiros. ${ }^{\text {xxix }}$

Este começo do discurso deu o sinal de que Lula retornaria, no discurso, às suas bases. Pois teria que ser aí, na origem, que deveria encontrar a força para enfrentar aquele momento. Mais do que um ato privado de um personagem o discurso de Lula deveria ser um ato público de defesa do PT, mas de um partido em que indivíduo e coletivo se confundem.

Lula negou ter cometido crime e asseverou: "O crime que cometi foi colocar pobre na universidade". Conclamou a militância a espalhar "Lulas por todo o país", pois "os poderosos podem matar uma, duas ou três rosas, mas jamais poderão deter a chegada da primavera", e após afirmar que confiava na Justiça, caso contrário não teria "feito um partido político", mas sim teria proposto uma revolução", comparou as medidas de seu governo à revolução: “A morte de um combatente não para uma revolução".

Na primeira parte deste artigo caracterizei o governo do PT e seus aliados como de Frente Popular que tentava se manter a partir de alianças cada vez mais amplas à direita e sustentando uma relação com os trabalhadores mediada pelos movimentos sociais, sindicatos e partidos de influência de massa. Essa política se assemelha ao populismo circunscrito ao período histórico de 1945 a 1964 no Brasil, em que pese não podermos classificar o governo de FP de populista. Ao discutir o "getulismo", entendido como os governos populistas do período 1945-64 (e não só Getúlio Vargas), no clássico “O colapso do populismo no Brasil”, o sociólogo Octávio Ianni salienta que "a política de massa foi a vida e a morte do modelo getuliano de desenvolvimento nacional. Quando não teve mais contrapartida nas diretrizes da política econômica, tornou-se inconveniente" (1988, p.67). Essa também parece ser a sentença para 
Lula e o PT: a relação com a massa é a vida e a morte do modelo lulista de desenvolvimento, que se sustentou enquanto houve crescimento econômico, quando não, tornou-se inconveniente para burguesia e se desprendeu das massas.

E como Vargas, em sua carta testamento, decretou sua imortalidade na história - "saio da vida para entrar na história" -, Lula decreta a imortalidade de seu sonho na vida da militância: "Não adianta parar o meu sonho, porque quando eu parar de sonhar, eu sonharei pela cabeça de vocês e pelos sonhos de vocês!".

Mesmo com esse simbolismo e popularidade de Lula o PT não foi capaz de mobilizar os trabalhadores na defesa de Dilma contra o impeachment ou o "golpe". E retomo o trecho citado de início, do 18 Brumario: "Cada partido ataca por trás aquele que procura empurrá-lo para a frente e apoia-se pela frente naquele que o empurra para trás. Não é de admirar que nessa postura ridícula perca o equilíbrio e, feitas as inevitáveis caretas, caia por terra em estranhas cabriolas” (MARX, 2008, p.48). O PT atacou por trás os trabalhadores que queriam empurrálo à frente, e se apoiou no PMDB que queria jogá-lo para trás. Por isso, caiu por terra.

\section{Considerações finais}

Por fim, devemos compreender toda essa história para além das fronteiras nacionais. Aqui sim talvez caiba a denominação de "onda", para se referir ao que ocorreu na América Latina nestas duas décadas iniciais do século XX. Vivemos uma onda (porque é fora da normalidade) de governos de Frente Popular: na Argentina dos Kirchner, Rafael Correa no Equador, Evo Morales na Bolívia, Mujica no Uruguai, Bachellet no Chile e Chávez e Maduro na Venezuela, em que pese o chavismo guardar diferenças sensíveis com os demais governos populares, por estar no escopo de um governo bonapartista (novamente o 18 brumario) mas sui generis.

Em todo caso, a FP no Brasil fora possível como também fora possível em outros países da América Latina, em vista de convergências históricas como: avanço dos movimentos sociais e da luta dos trabalhadores e da juventude que questionavam os planos neoliberais aplicados desde a década de 1990 no continente, e em alguns casos em vista da "crise de hegemonia" especialmente do lado da burguesia.

Esses governos, por conseguinte, se fizeram e se mantiveram (ou se mantém) enquanto há certo crescimento econômico. Neste sentido, a crise política é filha da crise econômica. Enquanto houve crescimento econômico, enquanto a crise do capitalismo mundial não chegou com toda a força ao Brasil, a oposição burguesa não tinha espaço para se impor. A partir do 
momento que a taxa de lucro caiu a patamares de recessão, os capitalistas passaram a não confiar mais em um governo que não é gerado no seu ventre.

Sem recursos para manter políticas compensatórias aos trabalhadores, pressionados pela burguesia a cortarem ainda mais dos pobres, e sem condições de manter a "paz social", esses governos são descartados. Mas, "haja o que houver”, Lula e o PT "sai da derrota mais humilhante, tão imaculado como era inocente quando entrou na questão, com a convicção recém-adquirida de que terá forçosamente de vencer, não porque ele e seu partido deverão abandonar o antigo ponto de vista, mas, pelo contrário, porque as condições têm de amadurecer para se porem de acordo com ele." (MARX, 2008, p.53).

A caracterização que o PT e parte da esquerda brasileira passaram a fazer da conjuntura pós-2016 como "estado de exceção", de ausência de democracia porque nos três poderes estaria havendo o desrespeito à ordem institucional, tenta recolocar como opção eleitoral outra ordem construída pela FP e interrompida no processo histórico aqui narrado: o pacto social em torno de Lula e o PT.

O caráter peculiar da socialdemocracia resume-se no fato de exigir instituições democráticorepublicas como meio não de acabar com dois extremos, capital e trabalho assalariado, mas de enfraquecer seu antagonismo e transformá-lo em harmonia. Por mais diferentes que sejam as medidas propostas para alcançar esse objetivo, por mais que sejam enfeitadas com concepções mais ou menos revolucionárias, o conteúdo permanece o mesmo. Esse conteúdo é a transformação da sociedade por um processo democrático, porém uma transformação dentro dos limites da pequena burguesia. (MARX, 2008, p.50)

E então voltamos a Marx.

\section{Referências}

CARDOSO, Adalberto Moreira. Dimensões da crise do sindicalismo brasileiro. Caderno CRH, Salvador, v. 28, p. 493-510, 2015.

DIAS, Edmundo Fernandes. Política brasileira: embate de projetos hegemônicos. São Paulo: Instituto José Luís e Rosa Sundermann, 2006.

DREIFUSS, René. A Conquista do Estado: ação Política e golpe de classe. Petrópolis: Vozes, 1981.

GODOY, Karine Rosa e RODRIGUES, Rodrigo Viela. Crescimento pró-pobre no Brasil: uma análise do período 2003-2013 para os estados brasileiros. Ensaios FEE. Porto Alegre, v.38, n.1, p.185-214, junho de 2017.

IANNI, Octávio. O colapso do populismo no Brasil. Rio de Janeiro: Civilização Brasileira, 1988.

LENIN, V. I. Esquerdismo, doença infantil do comunismo. 5 ed. São Paulo: Global, 1981 
MARINHO, Emerson, LINHARES, Fabricio, CAMPELO, Guaracyane. Os Programas de Transferência de Renda do Governo Impactam a Pobreza no Brasil?. RBE. Rio de Janeiro v. 65 n.3, p. 267-288, Jul-Set 2011 〈http://www.scielo.br/pdf/rbe/v65n3/a03v65n3.pdf>

(Acessado em em 11/5/2018)

MARX, Karl. As lutas de classes na França de 1848 a 1850. São Paulo: Boitempo, 2012.

MARX, Karl. A guerra civil na França. São Paulo: Boitempo, 2011.

MARX, Karl. O 18 Brumário de Luís Bonaparte. São Paulo: Martin Claret, 2008 (Coleção a obra-prima de cada autor).

MELO, Demian Bezerra de. O Golpe de 1964 e meio século de controvérsias: o estado atual da questão. In: MELO, D. B. de. (Org.). A miséria da historiografia: uma crítica ao revisionismo contemporâneo. Rio de Janeiro: Consequência, 2014, p.157-188.

OLIVEIRA, Vitor Wagner Neto de. Articulações comunistas em Mato Grosso (1935).

Cadernos de História. Belo Horizonte, v.16, n.24, p.51-67, $1^{\circ}$ semestre de 2015.

PIMENTA, Alexandre Marinho. O sindicalismo em 2013: entre a rua, a greve e o gabinete. In: IV Conferência Internacional "Greves e conflitos sociais. Crises do capitalismo, novas e velhas formas de protesto". São Paulo, FFLCH-USP, julho de 2018, s/p. GT 10 -GT10.

Conflitos do trabalho e sindicalismo - Sessão 04b: Lutas durante os governos progressistas na América Latina.

<http://www.iassc2018.sinteseeventos.com.br/simposio/view?ID_SIMPOSIO=14> (Acessado em 14/5/2018)

SAGRA, Alicia. A Internacional: um permanente combate contra o oportunismo e o sectarismo. São Pauo: Sundermann, 2010.

TATAGIBA, Luciana. 1984, 1992 e 2013: sobre ciclos de protestos e democracia no Brasil. Política \& Sociedade. 2014, vol:13, n:28, p. 35 -62.

<https://periodicos.ufsc.br/index.php/politica/article/view/2175-7984.2014v13n28p35/28900>

TERRON, Sonia Luiza, SOARES, Glaúcio Ary Dillon. As bases eleitorais de Lula e do PT: do distanciamento ao divórcio. Opinião pública. Campinas, vol.16, n.2, p.310-337, novembro 2010 .

WAISELFISZ, Julio Jacobo. Mapa da violência 2015: homicídio de mulheres no Brasil. Brasília-DF: FLACSO Brasil, 2015.

Recebido: $26 / 04 / 2021$

Aceito: $18 / 07 / 2021$

Publicado: 01/09/2021

\footnotetext{
* Professor Associado da Universidade Federal de Mato Grosso do Sul, Campus de Três Lagoas. Lattes: http://lattes.cnpq.br/5198035447754383. Orcid: https://orcid.org/0000-0003-2008-4195.

${ }^{\mathrm{i}} \mathrm{O}$ termo assim composto indica a compreensão de que a ditadura de 1964 a 1985 foi um projeto implementado pela burguesia brasileira em parceria com as Forças Armadas. A utilização deste termo, empresarial-militar, qualifica e explicita a compreensão do termo "civil-militar", cunhado por René Dreifuss (1981), em contraposição à utilização que a historiografia revisionista da ditadura tem feito do termo composto (civil-militar) em que "civil"
} 
indicaria o apoio popular ao regime e mesmo a participação popular na ditadura. Sobre este debate, ver Demian Melo (2014).

ii Presidência da República. Lei n. 6.883, de 28 de agosto de 1979. $<$ http://www.planalto.gov.br/ccivil_03/leis/L6683.htm> (Acessado em 10/5/2018)

iii Câmara dos Deputados. Lei n. 6.767, de 20 de dezembro de 1979. Legislação informatizada. <https://www2.camara.leg.br/legin/fed/lei/1970-1979/lei-6767-20-dezembro-1979-357280-publicacaooriginal-1pl.html> (Acessado em 10/5/2018)

${ }^{\text {iv }}$ Frente Única: tática adotada pela III Internacional a partir do $3^{\circ}$ e $4^{\circ}$ Congressos (1921 e 1922) que concebia a unidade dos comunistas com partidos operários sociais-democratas em um contexto de recrudescimento dos ataques da direita, crescimento da ultradireita (surgimento do nazismo) e do arrefecimento do movimento revolucionário na Europa. Os escritos de Lenin "Esquerdismo, doença infantil do comunismo", são frutos da discussão que levou a adoção dessa tática pelos comunistas (LENIN, 1981).

v O PPS surgiu em 1992 de uma cisão do PCB na crise que abateu a esquerda após a queda do Muro de Berlim.

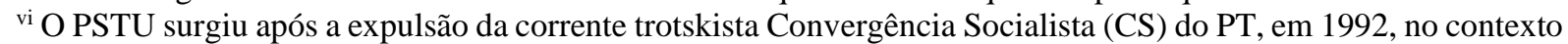
de grandes mobilizações. Diante do aumento da rejeição dos trabalhadores e da juventude ao presidente liberal Fernando Collor de Melo, os militantes da CS defendiam a consigna de "Fora Collor" e a corrente majoritária do PT defendia a governabilidade para desgastar o governo e disputar as eleições em 1994 com maiores chances. Essa disputa interna já indicava o distanciamento do PT dos princípios da origem do Partido que passava a apostar prioritariamente na eleição em todos os níveis (do município, estado e união).

vii Uma análise do desempenho e da base eleitoral de Lula e do PT de 1994 a 2002 pode ser lida em Sonia Terron e Gláucio Soares (2010).

viii Folha de São Paulo. "Leia íntegra da carta de Lula para acalmar o mercado financeiro". 24/6/2002. Folha Online. <http://www1.folha.uol.com.br/folha/brasil/ult96u33908.shtml> (Acessado em 9/5/2018).

ix Idem.

x O revolucionário russo Leon Trotsky produziu diversas análises sobre a tática de Frente Única e Frente Popular. Neste sentido ver Alicia Sagra (2010).

xi Ver Vitor Oliveira (2015).

xii SASSATELLI, Frei Marcos. "Por uma frente ampla e popular". 30/6/2017. <http://www.frentebrasilpopular.org.br/artigos/por-uma-frente-ampla-e-popular-2a48/> $\quad$.PCdoB. "PCdoB: Mudanças com a construção de uma Frente Ampla". 18/2/2018. < https://pcdob.org.br/noticias/pcdob-df-mudancacom-a-construcao-de-uma-frente-ampla/ (Acessado em 10/5/2018)

xiii G1. Economia, 6/5/2015. <http://g1.globo.com/economia/mercados/noticia/2015/05/preco-do-petroleo-atingemaximas-de-2015-com-queda-de-estoques.html> (Acessado em 11/5/2018)

xiv BBC. Brasil, 1/12/2015. <http://www.bbc.com/portuguese/noticias/2015/12/151201_pib terceirotri2015 ru > (Acessado em 11/5/2018)

xv FATORELLI, Maria Lúcia. “O que provocou a crise econômica atual?” Auditoria cidadã da dívida. Artigos na ACD. 19 de junho de 2017. <https://auditoriacidada.org.br/conteudo/o-que-provocou-crise-economica-atual/> (Acessado em 18/5/2018).

xvi Extra classe. Entrevista Maria Lucia Fattorelli. Deixamos de dever ao FMI para dever aos bancos. $<$ https://www.extraclasse.org.br/edicoes/2015/10/deixamos-de-dever-ao-fmi-para-dever-aos-bancos/> (Acessado em 18/5/2018)

xvii <http://www1.folha.uol.com.br/fsp/dinheiro/fi2202200802.htm> (Acessado em 11/5/2018)

xviii UOL. $\quad$ Economia. 31/01/2018. $\quad$ https://economia.uol.com.br/empregos-ecarreiras/noticias/redacao/2018/01/31/desemprego-quarto-trimestre-ibge.htm> (Acessado em 11/5/2018)

xix NEXO. Especial (por Daniel Mariani, Bruno Lupion e Rodolfo Almeida). 2/12/2016. <https://www.nexojornal.com.br/especial/2016/09/02/10-índices-econômicos-e-sociais-nos-13-anos-de-governoPT-no-Brasil> (Acessado em 11/5/2018)

${ }^{\mathrm{xx}}$ Não se tem acordo na literatura sobre a "linha de pobreza", ou seja, o que levar em conta para considerar a pobreza e a miséria, por isso aqui estamos acompanhando as definições das fontes consultadas para os índices. Ver (MARINHO, LINHARES, CAMPELO, 2011, p. 269).

xxi Folha UOL. 26/5/2002. <http://www1.folha.uol.com.br/fsp/brasil/fc2605200212.htm> (Acessado em $11 / 5 / 2018)$

xxii O Índice de Gini, criado pelo matemático italiano Conrado Gini, é uma metodologia que mede o grau de concentração de renda.

xxiii Pesquisa Nacional por Amostra de Domicílio realizada pelo Instituto Brasileiro de Geografia e Estatísticas (IBGE).

xxiv $O$ Globo. 25/2/2011. <https://oglobo.globo.com/economia/na-era-lula-bancos-tiveram-lucro-recorde-de-199bilhoes-2818232> (Acessado em 14/5/2018). CONECT Brasil. Boletim econômico. N.82, setembro de 2014. <https://www.contec.org.br/attachments/article/12220/Boletim\%20Econ\%C3\%B4mico\%20da\%20CONTEC\%2 0N\%C2\%BA\%2082.pdf> (Acessado em 14/5/2018). 
xxv DIEESE. Balanço das greves de 2013. Estudos e pesquisas. N.79, dezembro de 2015 <https://www.dieese.org.br/balancodasgreves/2013/estPesq79balancogreves2013.pdf> (Acessado em 14/5/2018). xxvi Ver Luciana Tatagiba (2014) Sobre os ciclos de protestos no Brasil, uma análise comparativa entre as manifestações pelas “Diretas Já” em 1984, "Fora Collor” em 1992 e "Jornadas de Junho" em 2013.

xxvii Carta Capital. Carta nas eleições. 7/10/2014. <https://www.cartacapital.com.br/blogs/carta-naseleicoes/soma-de-votos-nulos-brancos-e-abstencoes-e-a-maior-desde-1998-6625.html> (Acessado em $16 / 5 / 2018)$.

xxviii G1. Eleições 2016. 〈http://g1.globo.com/politica/eleicoes/2016/noticia/2016/10/abstencoes-votos-brancos-enulos-somam-326-do-eleitorado-do-pais.html> (Acessado em 16/5/2018)

xxix Estadão. "Política. Doações de campanha somam R\$ 1 bi, das quais metade em de 19 empresas". 15/9/2014. $<$ http://politica.estadao.com.br/noticias/geral,doacoes-de-campanha-somam-r-1-bi-das-quais-metade-vem-de-19empresas-imp-,1560289> (Acessado em 16/5/2018).

xxx <https://g1.globo.com/politica/eleicoes/2018/noticia/2018/10/09/tse-conclui-apuracao-do-primeiro-turno-796dos-eleitores-foram-as-urnas.ghtml (Acessado em 07/11/2018).

xxxi <https://g1.globo.com/politica/eleicoes/2018/eleicao-em-numeros/noticia/2018/10/28/percentual-de-votonulo-e-o-maior-desde-1989-soma-de-abstencoes-nulos-e-brancos-passa-de-30.ghtml> (Acessado em 07/11/2018) xxxii DIEESE. Balanço das greves de 2016. Estudos e pesquisas. N.84, agosto de 2017 <https://www.dieese.org.br/balancodasgreves/2016/estPesq84balancogreves2016.html> (Acessado em $14 / 5 / 2018)$

xxxiii Em 2016 a população prisional no Brasil atingiu a marca de 726.712 pessoas, terceira população carcerária do mundo. $64 \%$ da população prisional é composta por pessoas negras, enquanto que a população negra brasileira acima dos 18 anos é de 53\% (ver INFOPEN, 2017, p.32). Em junho de 2016, conforme a mesma fonte, $40 \%$ das pessoas presas no Brasil não haviam sido ainda julgadas e condenadas (Ver, INFOPEN, 2017, p.13). Em 2003 a população carcerária era de 308.304. Em 13 anos de governo de FP a população carcerária mais do que dobrou. INFOPEN. SANTOS, T. (org.) ROSA, M. I. et al (col.). Levantamento nacional de informações. Atualização junho de 2016. Brasília: Ministério da Justiça e Segurança Pública. Departamento Penitenciário Nacional, 2017. $<$ http://depen.gov.br/DEPEN/noticias-1/noticias/infopen-levantamento-nacional-de-informacoes-penitenciarias2016/relatorio_2016 22111.pdf> (Acessado em 16/5/2018)

xxxiv Números da violência no Brasil. De 2003 a 2013 observa-se um movimento contraditório: decresce em $11 \%$ o homicídio de mulheres brancas e aumenta em 19\% o homicídio de mulheres negras (WAISELFISZ, 2015, p.73). xxxv Instituto Socioambiental. "O que o governo Dilma fez (e não fez) pela reforma agrária?" <https://www.socioambiental.org/pt-br/noticias-socioambientais/o-que-o-governo-dilma-fez-e-nao-fez-pelareforma-agraria> (Acessado em 14/5/2018)

xxxvi Conselho Indigenista Missionário-CIMI. Relatório: Violência contra os povos Indígenas no Brasil - Dados de 2015. <https://cimi.org.br/pub/relatorio/Relatorio-violencia-contra-povos-indigenas_2015-Cimi.pdf> (Acessado em 03/07/2020)

xxxvii Folha de São Paulo. “Bolsa empresário' supera gastos com programas sociais”. <http://www1.folha.uol.com.br/mercado/2017/08/1907561-bolsa-empresario-superabrprogramas-sociais.shtml> (Acessado em 14/5/2018).

xxxviii INEP. Censo da educação superior 2016: divulgação. Brasília-DF: Ministério da Educação, 31 de agosto de 2017. <https://abmes.org.br/arquivos/documentos/apresentacao censo educacao superior.pdf> (Acessado em $18 / 5 / 2018)$.

xxxix TV 247. “A íntegra do discurso de Lula no dia de sua prisão”. Youtube. <https://www.youtube.com/watch?v=FRccgZFYk8I > (Acessado em 16/5/2018) 